\title{
Hearing Function in Heterozygous Carriers of a Pathogenic GJB2 Gene Mutation
}

\author{
D. GROH ${ }^{1,2}$, P. SEEMAN ${ }^{3}$, M. JILEK ${ }^{1}$, J. POPELÁ ${ }^{1}{ }^{1}$, Z. KABELKA ${ }^{2}$, J. SYKA $^{1}$ \\ ${ }^{1}$ Department of Auditory Neuroscience, Institute of Experimental Medicine AS CR, Prague, Czech \\ Republic, ${ }^{2}$ Department of Otorhinolaryngology, Second Faculty of Medicine, Charles University \\ in Prague and University Hospital Motol, Prague, Czech Republic, ${ }^{3}$ Department of Pediatric \\ Neurology, Second Faculty of Medicine, Charles University in Prague and University Hospital \\ Motol, Prague, Czech Republic
}

Received October 12, 2012

Accepted January 3, 2013

On-line March 14, 2013

\section{Summary}

The most frequent hereditary hearing loss is caused by mutations in the GJB2 gene coding for the gap junction beta 2 protein Connexin 26 (Cx26). In contrast to many studies performed in patients with bi-allelic mutations, audiometric studies on heterozygotes are sparse and often contradictory. To evaluate hearing function in heterozygous carriers of the GJB2 c.35delG mutation, audiometry over the extended frequency range and the recording of otoacoustic emissions (OAEs), i.e., transient-evoked OAEs (TEOAEs) and distortion product OAEs (DPOAEs), were performed in a group of parents and grandparents of deaf children homozygous for the GJB2 c.35delG mutation. The comparison of audiograms between control and heterozygous subjects was enabled using audiogram normalization for age and sex. Hearing loss, estimated with this procedure, was found to be significantly larger in GJB2 c.35delG heterozygous females in comparison with controls for the frequencies of $8-16 \mathrm{kHz}$; the deterioration of hearing in heterozygous men in comparison with controls was not statisticaly significant. A comparison of TEOAE responses and DPOAE levels between GJB2 c.35delG heterozygotes and controls did not reveal any significant differences. The results prove the importance of using audiometry over the extended frequency range and audiogram normalization for age and sex to detect minor hearing impairments, even in a relatively small group of subjects of different ages.

\section{Key words}

c.35delG mutation - Audiogram normalization - High-frequency audiometry • Otoacoustic emissions • High-frequency hearing loss

\section{Corresponding author}

Daniel Groh, Department of ENT, Charles University in Prague, $2^{\text {nd }}$ Faculty of Medicine, V Úvalu 84, 15006 Prague 5, Czech Republic. Fax: (+420) 224432620.

E-mail: daniel.groh@seznam.cz

\section{Introduction}

Sensorineural hearing loss is a very common inherited sensory defect affecting 1-2 per 1000 newborns. Until now, mutations in more than 39 different genes have been identified as resulting in non-syndromic autosomal recessive deafness (http://hereditaryhearingloss .org). About $50 \%$ of these cases are caused by mutations in the GJB2 gene coding for the gap junction beta 2 protein Connexin $26(\mathrm{Cx} 26)$, resulting in a hereditary hearing loss named DFNB1. Gap junctions in the inner ear have been shown to recycle potassium ions from the hair cells to the endolymph (Holt and Corey 1999). About $3 \%$ of the Caucasian population are heterozygous for the c.35delG mutation in the GJB2 gene (the deletion of a single guanosine in a sequence of six guanosines extending from position 30 to position 35) (Seeman et al. 2004).

Several previous studies have documented moderate to profound hearing loss in homozygotes for the c.35delG mutation (Kelsell et al. 1997, Murgia et al. 1999). However, audiometric results obtained in GJB2 heterozygotes are sparse and often contradictory. EngelYeger et al. (2002) as well as Silva et al. (2010) did not 
find any differences in the audiograms of carriers and non-carriers, but they demonstrated a significantly lower response level of DPOAEs in carriers in comparison with non-carriers. Other studies reported statistically significant differences in hearing thresholds, mainly at high frequencies (Wilcox et al. 2000, Franzé et al. 2005, Lipan et al. 2011), and/or lower DPOAE response levels over a limited frequency range (Silva et al. 2010). These studies were performed in small cohorts of subjects, and hearing thresholds were often measured only in the conventional frequency range up to $8 \mathrm{kHz}$.

The aim of the present study was to evaluate hearing function in a group of heterozygous parents and grandparents of 18 congenitally hearing-impaired children that were homozygous for the GJB2/c.35delG mutation. Hearing in heterozygous parents and grandparents was evaluated using audiometry over the extended frequency range up to $16 \mathrm{kHz}$ and the recording of OAEs.

\section{Methods}

Audiometric testing was performed in a group of 122 healthy control subjects and in a group of 34 parents and grandparents of 18 congenitally hearing-impaired children previously identified for the implantation of a cochlear implant in the University Hospital Motol in Prague. All 18 children were homozygous for the c.35delG mutation in the GJB2 gene. All subjects had normal results from an otoscopic examination.

The genotyping procedures and audiometric recordings were approved by the Ethics Committee of the University Hospital Motol, Prague, and followed the guidelines of the Declaration of Helsinki.

\section{Genetic testing}

The group of 52 parents and grandparents of
18 congenitally hearing-impaired children were examined for the presence or absence of the $G J B 2 / \mathrm{c} .35 \mathrm{delG}$ mutation using a combination of allele-specific polymerase chain reaction (PCR) and fluorescence PCR with subsequent fragment analysis, as described elsewhere (Seeman et al. 2004). Deoxyribonucleic acid (DNA) was isolated from the saliva using a commercial kit Oragene. From the total number of 52 relatives, 34 parents and grandparents (65\%) (13 males and 21 females) were found to be heterozygous for the c. $35 \mathrm{delG}$ mutation. The age and gender of all subjects are shown in Table 1.

\section{Pure tone audiometry}

Hearing thresholds were obtained bilaterally over an extended frequency range from $125 \mathrm{~Hz}$ up to $16 \mathrm{kHz}$ using a clinical audiometer (OB 922, Madsen Orbiter, v.2) equipped with high-frequency headphones (HDA 200, Sennheiser).

\section{Audiogram normalization procedure}

Due to age-related hearing loss, the hearing thresholds in individual experimental groups can be compared only between subjects of the same age. For comparing the hearing thresholds of persons of different age and sex, the audiograms were normalized. The agerelated threshold shift at frequencies from $125 \mathrm{~Hz}$ to $8 \mathrm{kHz}$ is defined in the ISO 7029 standard by a mathematical equation. In this standard, $\alpha$ coefficients for each frequency are given for males and females separately. However, no coefficients are presented for audiometry in the extended frequency range used in this study. In the paper by Jilek and Syka (2008), the $\beta$ coefficients for frequencies of $10,12.5$ and $16 \mathrm{kHz}$ were calculated using a linear approximation method. These coefficients were used for audiogram normalization in the extended frequency range.

Table 1. Distribution of control and heterozygous males and females by age (in decades).

\begin{tabular}{lcccccc}
\hline $\begin{array}{l}\text { Age group } \\
\text { (years) }\end{array}$ & Males & Females & All & Males & Females & All \\
\cline { 2 - 7 } & 13 & 12 & 25 & 3 & 6 & 9 \\
$26-34$ & 10 & 11 & 21 & 3 & 2 & 5 \\
$35-44$ & 7 & 15 & 22 & 2 & 2 & 4 \\
$45-54$ & 16 & 15 & 31 & 3 & 9 & 12 \\
$55-64$ & 10 & 13 & 23 & 2 & 2 & 4 \\
$>65$ & $\mathbf{5 6}$ & $\mathbf{6 6}$ & $\mathbf{1 2 2}$ & $\mathbf{1 3}$ & $\mathbf{2 1}$ & $\mathbf{3 4}$ \\
Total & & & & & & \\
\hline
\end{tabular}




\section{Average audiograms}
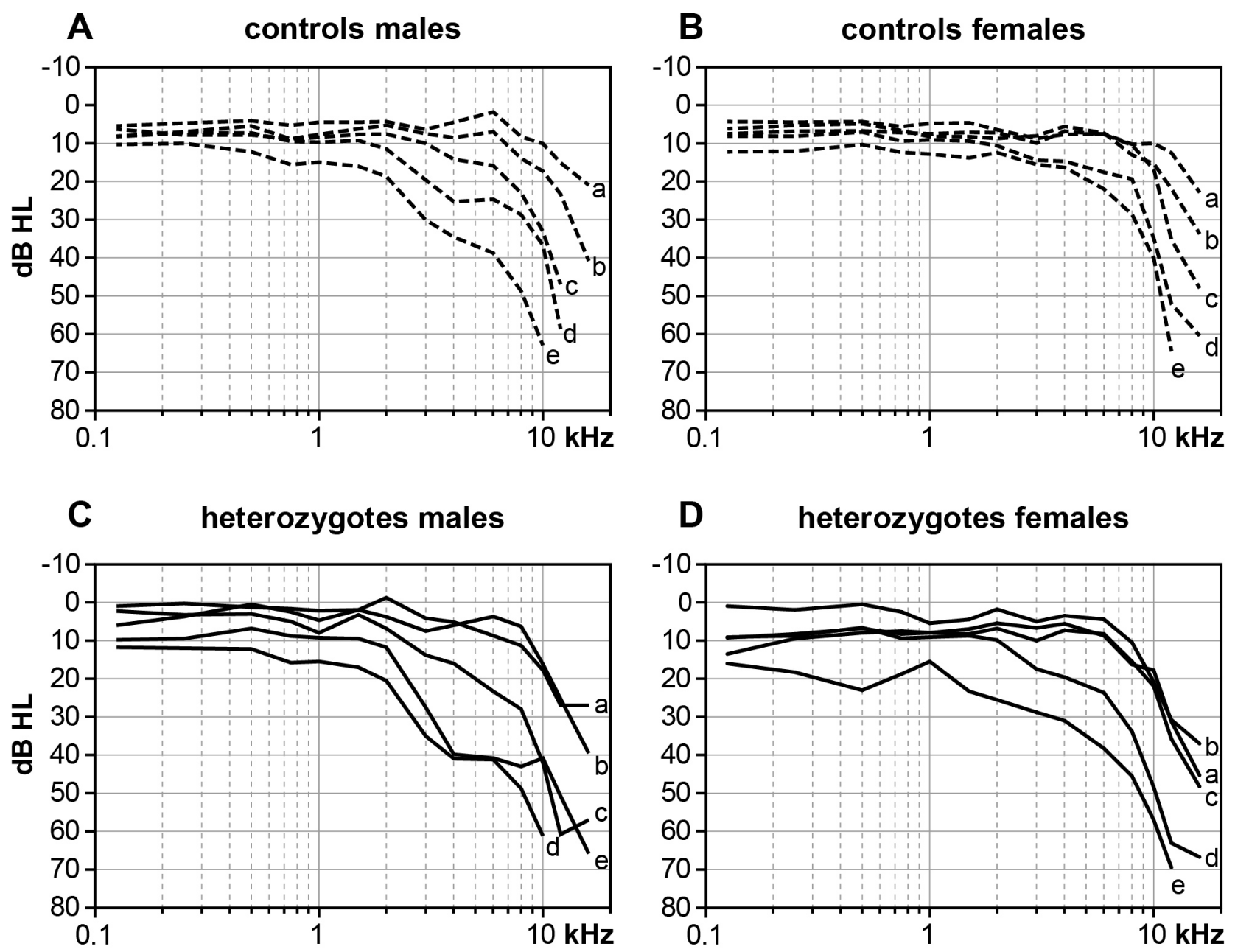

Fig. 1. Audiograms of controls and heterozygotes averaged in age decades for males (A, C) and females (B, D). Age decades: a=2534 y, b=35-44 y, c=45-54 y, d=55-64 y, e= over 65 y

\section{Recording of otoacoustic emissions}

To examine the physiological status of outer hair cells (OHCs) in the cochlea otoacoustic emissions were measured with commercial instrumentation (ILO 292, Otodynamics, Ltd.) using a B-type probe for adults. The signal was processed with an ILO software (Otodynamics, Ltd., v.6).

The acoustical stimuli for transiently evoked otoacoustic emissions (TEOAEs) were conventional broadband clicks $(0.5-6.0 \mathrm{kHz}, 80 \mu$ s duration), with the stimulus gain adjusted to $80 \mathrm{~dB}$ peak SPL. Each recording consisted of 260 averagings. Only measurements with a reproducibility of more than $60 \%$ were considered.

Stimuli for eliciting $2 \mathrm{f}_{1}-\mathrm{f}_{2}$ distortion-product otoacoustic emissions (DPOAEs) (cubic DPOAEs) were two primary tones, $\mathrm{f}_{1}$ and $\mathrm{f}_{2}$, with tone levels $\mathrm{L} 1=\mathrm{L} 2=$ $70 \mathrm{~dB}$ SPL, $\mathrm{f}_{2} / \mathrm{f}_{1}=1.22$. Testing was made over the $\mathrm{f}_{2}$ frequency range from $1-6.3 \mathrm{kHz}$, at three points/octave. The DPOAE values as a function of $f_{2}$ frequency (DPgrams) in individual subjects are presented here.

\section{Statistical tests}

Differences between hearing thresholds and DPgrams in control versus heterozygous subjects were tested using one-way ANOVA with the Bonferroni post-hoc test. Average TEOAE responses, measured in control and heterozygous subjects, were compared using a t-test. All statistical calculations were performed using commercial software (GraphPad, v.7, SigmaPlot). 


\section{Average normalized audiograms}

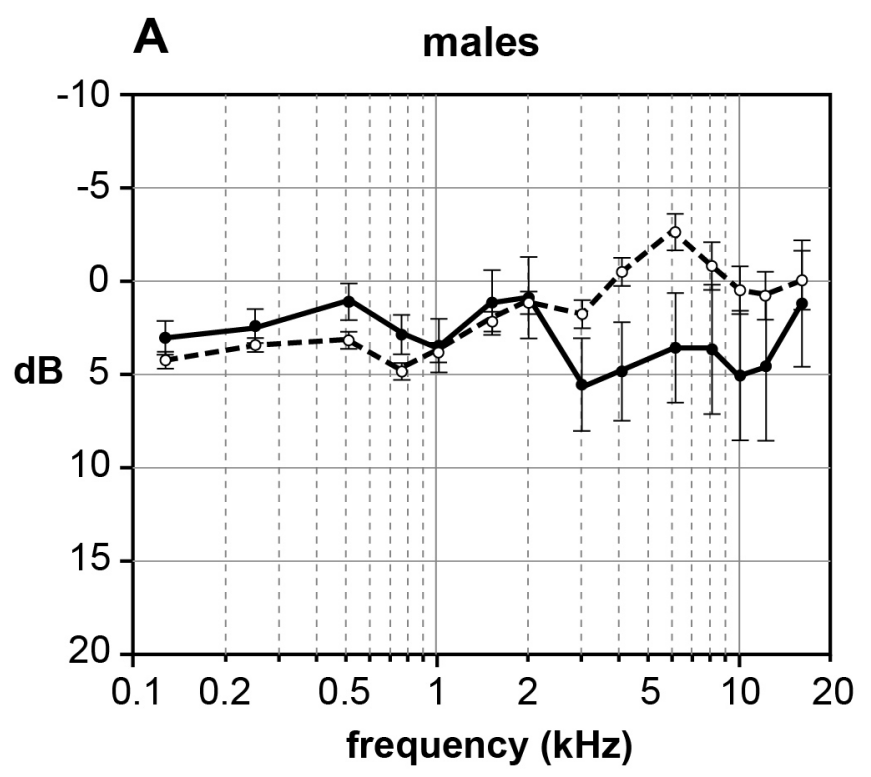

B females

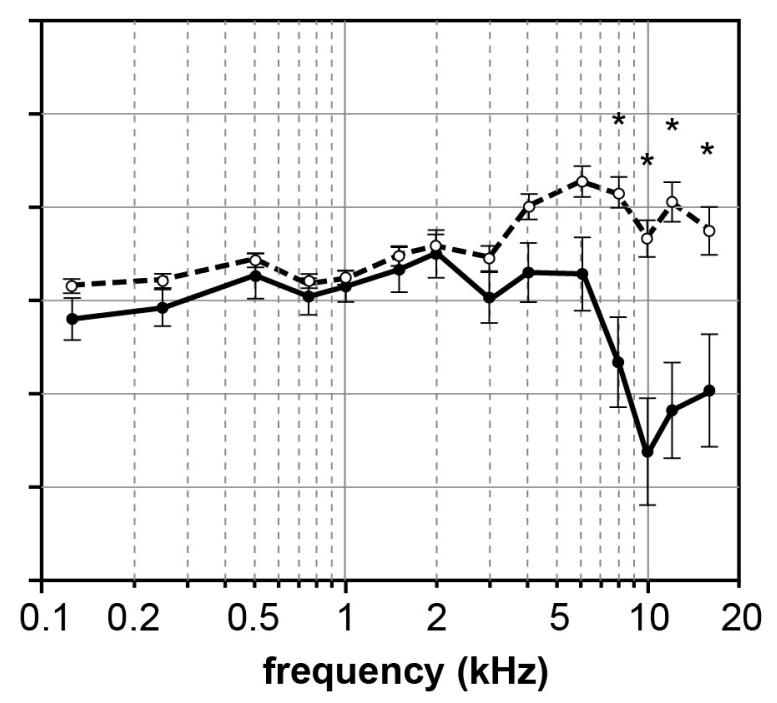

\section{.-.. controls - heterozygotes}

Fig. 2. Averaged normalized audiograms of heterozygous $(n=13)$ and control $(n=56)$ males $(\mathbf{A})$ and heterozygous $(n=21)$ and control $(n=66)$ females $(B) .(* p<0.0001)$. Error bars represent \pm standard error of the mean.

\section{Results}

\section{Hearing thresholds}

Figure 1 shows the audiograms averaged over decades in controls (Fig. $1 \mathrm{~A}, \mathrm{~B}$ ) and heterozygous carriers (Fig. $1 \mathrm{C}, \mathrm{D})$, separately for males (A, C) and females (B, D).

\section{Hearing threshold normalization for age and sex}

To enable the comparison of audiograms between heterozygous carriers and controls, the procedure of audiogram normalization for sex and age was used. The average normalized audiograms of control males and females (Fig. 2A, B, interrupted lines) are almost identical; the differences between the normalized thresholds at individual frequencies did not exceed $1.3 \mathrm{~dB}$, thus providing evidence of the reproducible results achieved by using audiogram normalization. The average normalized audiograms for heterozygous males and females (Fig. 2A, B, full lines) show a pronounced hearing loss at frequencies higher than $2 \mathrm{kHz}$. Normalized audiograms in control males and heterozygous males are not significantly different. However, the audiograms obtained in heterozygous females are significantly worse at frequencies of 8-16 $\mathrm{kHz}$ than those measured in control females $(\mathrm{p}<0.0001)$.
To analyze more precisely the hearing impairment in heterozygous subjects, the normalized high-frequency (HF) thresholds in the frequency range 8-16 kHz were averaged for each heterozygous male and female and compared with the analogous data obtained in controls. The mean HF thresholds in control males amounted to $0.15 \pm 12.2 \mathrm{~dB}$ HL and $3.63 \pm 16.8 \mathrm{~dB}$ HL in heterozygous males $(\mathrm{p}<0.222$, t-test). The histograms in Fig. 3A document that $34.9 \%$ of controls and $34.6 \%$ of heterozygotes had their $\mathrm{HF}$ thresholds concentrated at around $0 \mathrm{~dB}$ HL. In females, the mean HF thresholds in heterozygous females $(10.63 \pm 2.302 \mathrm{~dB}$ HL) significantly exceeded the mean HF thresholds found in the control females $\quad(0.4780 \pm 0.733$ dB HL $) \quad(p<0.0001, \quad t$-test $)$. Whereas $45.8 \%$ of control females had HF thresholds at around $0 \mathrm{~dB} \mathrm{HL}$, the largest number of heterozygous females $(35.7 \%)$ had HF thresholds located at around $10 \mathrm{~dB}$ HL (Fig. 3B).

\section{DPOAES}

The average DP grams evaluated in selected agematched controls and GJB2 heterozygous carriers are presented in Fig. 4. The differences between the average DP-grams evaluated in control and heterozygous males (Fig. 4A) and control and heterozygous females (Fig. 4B) are not significant at any frequency. 

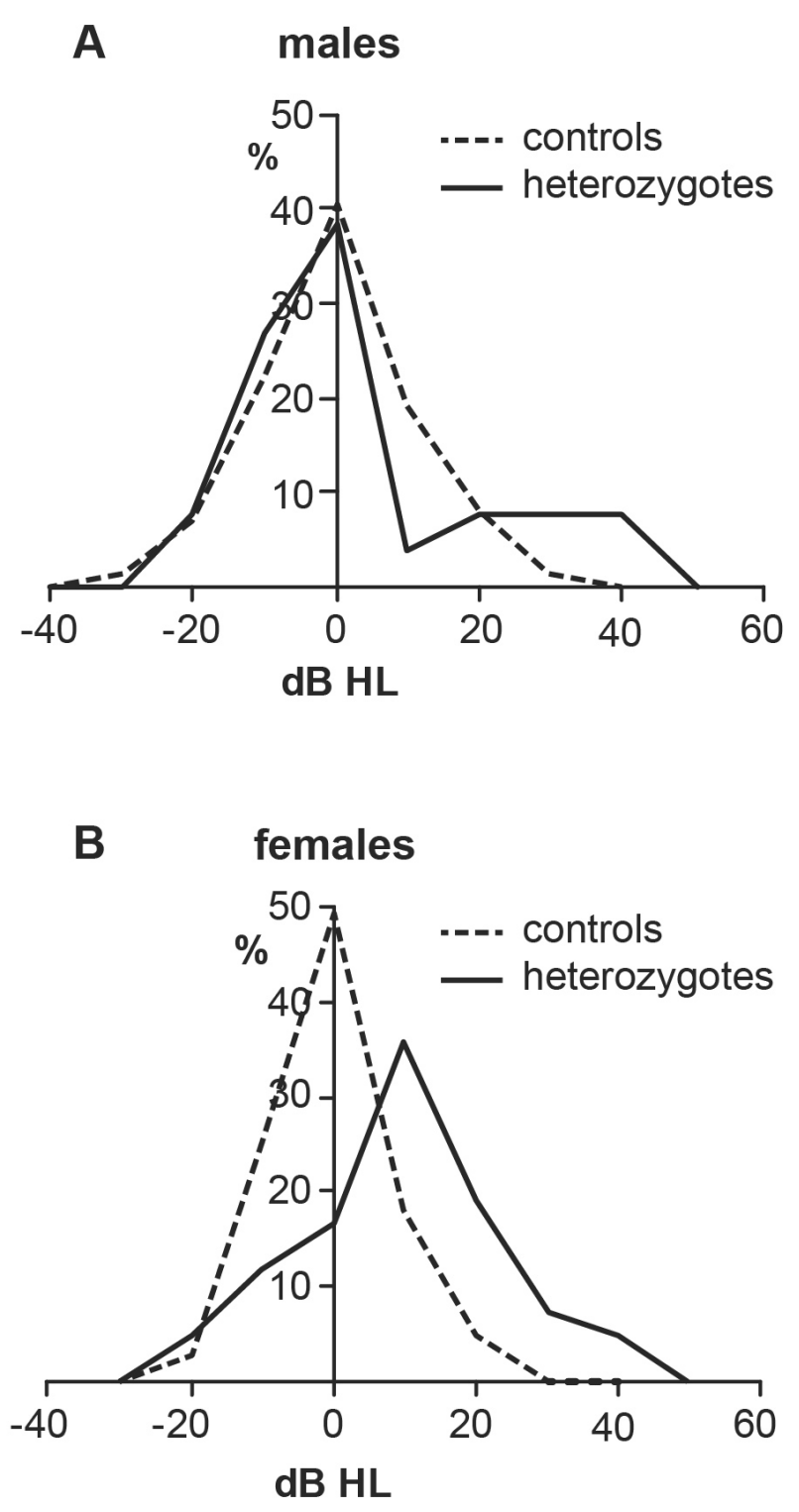

Fig. 3. Histograms of the average normalized HF thresholds $(8-16 \mathrm{kHz})$ in control and heterozygous males (A) and females (B).

\section{TEOAEs}

The TEOAE responses averaged in heterozygous carriers and control males and females are shown in Figure 5. Similarly to DPOAEs, the average TEOAE responses measured in heterozygous carriers and control males and females are not statistically different.

\section{Discussion}

The results of the present study demonstrate that the analysis of TEOAE responses and DPOAE levels did not show significant differences between $G J B 2$ c.35delG heterozygotes and controls. However, using audiometry in an extended frequency range and the methods of

\section{Average DP-grams}

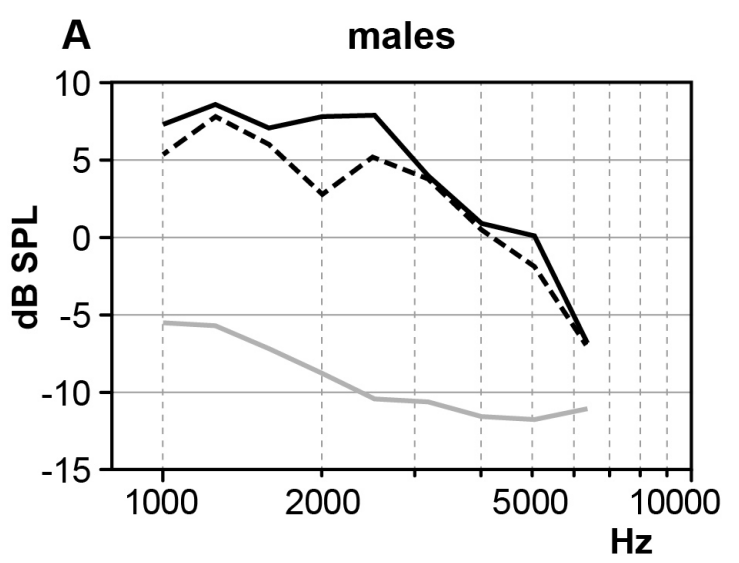

B females

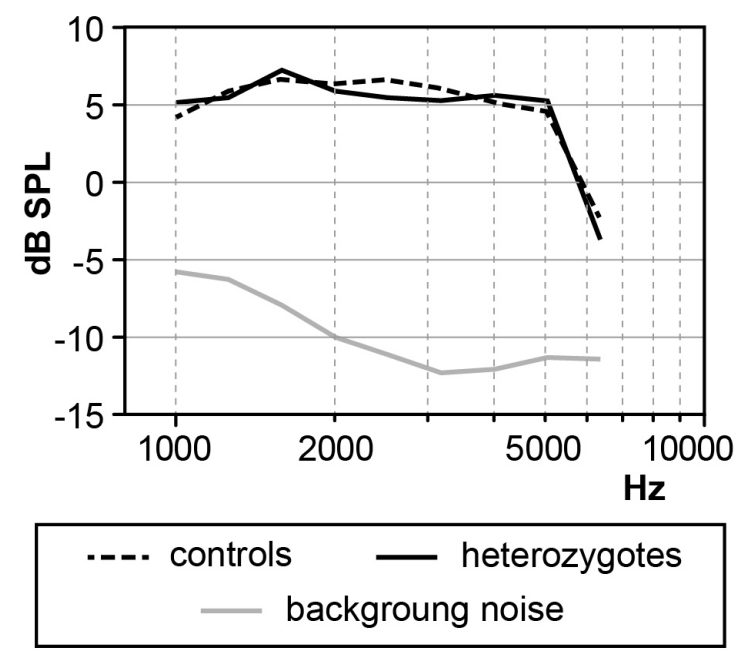

Fig. 4. Average DP-grams for control and heterozygous males (A) and females (B).

audiogram normalization according to age and sex, a significant hearing loss at frequencies of $8-16 \mathrm{kHz}$ was detected in heterozygote woman in comparison to control woman. The difference between the normalized audiograms in control males and heterozygous men was not statistically significant. These results document the importance of high frequency audiometry and the suitability of audiogram normalization methods for detecting small differences in the audiometric hearing loss of a small number of subjects with large differences in age.

Mutations in the GJB2 gene represent the most common cause of recessively inherited hearing loss (Petersen and Willems 2006). There have been several publications dealing with the large variability in genetic background and phenotype-genotype deafness. Most of 


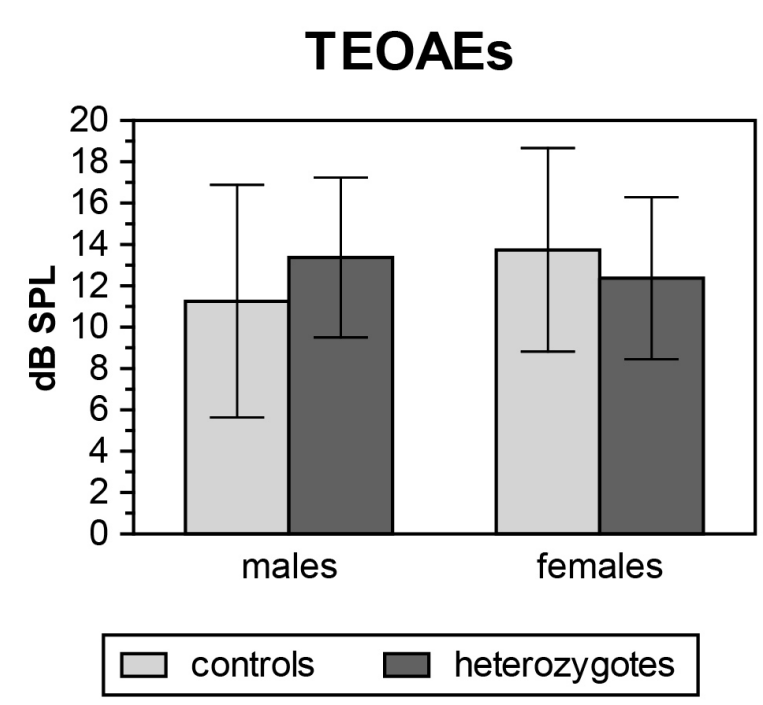

Fig. 5. Average TEOAE responses for control and heterozygous males and females. Error bars represent \pm standard deviation.

these studies were oriented towards a detailed identification of the bi-allelic GJB2 mutations causing hearing loss of different severity or even deafness (Cohn and Kelley 1999); only in a few studies have the audiometric manifestations of a heterozygous pattern been systematically studied. Due to the small number of subjects with a GJB2 gene mutation in the normal population (2-4\%) (Seeman et al. 2004) and the large variability of hearing loss in these heterozygous subjects (from normal hearing to profound hearing loss), studies examining hearing function in GJB2 c.35delG heterozygotes have often yielded contradictory results. Engel-Yeger et al. (2002) found a significant difference between non-carriers and c.35delG carriers: non-carriers had larger DPOAE responses than heterozygotes at all frequencies. In contrast to a significant difference in DPOAEs, the hearing thresholds of carriers and noncarriers were found to be similar up to $8 \mathrm{kHz}$. The large variability of hearing loss in a group of heterozygous carriers of the GJB2 $35 \mathrm{delG}$ mutation was reported in several other studies (Wilcox et al. 2000, Franzé et al. 2005, Lipan et al. 2011). In our study the tested subjects were parents or grandparents of congenitally hearingimpaired children who were diagnosed as having the c.35delG mutation. Such a sample of probands guarantees a high probability of the presence of the c.35delG mutation. A similar strategy, i.e., audiological evaluation of the heterozygous parents of individuals with autosomal recessive hearing loss, was used in the study of Silva et al. 2010. These authors found a tendency towards better audiometric thresholds in the control group in comparison with the heterozygous parents, but without statistical significance.

Due to the large age range of heterozygotes in our study (from 30 to $70 \mathrm{y}$ ), it was not possible to divide the total number of heterozygous subjects into smaller age groups and to compare their audiograms with those of the corresponding age groups of the control subjects. To overcome this limitation, the method of normalizing all of the audiograms for age and sex was used. Audiogram normalization for every frequency in the frequency range $0.125-8 \mathrm{kHz}$ was performed using $\alpha$ coefficients according to the ISO 7029 standard, while for frequencies of $10,12.5$ and $16 \mathrm{kHz}$ the $\beta$ coefficients were calculated using a linear approximation method (Jilek and Syka 2008). This procedure enabled us to detect a pronounced hearing threshold elevation at high frequencies that was statistically highly significant in females, but not in males. This result was confirmed by computing the average HF threshold (i.e., the average of the threshold values at frequencies of $8-16 \mathrm{kHz}$ ). The distribution histograms of the average HF thresholds demonstrated the differences between the mechanisms of hearing impairment between heterozygous males and females: whereas the distribution histogram of the average HF threshold values in heterozygous males is almost identical with that obtained for control males and only a minority exhibited a relatively large threshold deterioration, the distribution histogram of the average HF threshold values in heterozygous females was significantly shifted by approximately $10 \mathrm{~dB}$ to higher values compared to control values, suggesting the presence of HF hearing deterioration in a large portion of heterozygous females. Hearing impairment of heterozygous females seems be not age-dependent since pronounced hearing loss was detected in several young as well as old heterozygous females. To the best of our knowledge, this paper represents the first study reporting a significantly worse deterioration of hearing function in c.35delG heterozygous females than in heterozygous males.

Impaired potassium recycling in Connexin 26 (Cx26) mutants may cause a fluid and ion imbalance in the cochlea and change the endolymphatic potential, which is necessary for the proper functioning of the OHCs and the inner hair cells (IHCs) (Kikuchi et al. 2000). Since OHC impairment due to a GJB2 mutation may be reflected in impaired OAEs, our original hypothesis was that the OAEs in GJB2 c.35delG heterozygous carriers could be altered as well. 
Unfortunately, the method of audiogram normalization is not possible to use in the case of OAE recording, and thus no significant differences were detected in the average TEOAE responses or in the DPOAE amplitudes between heterozygous and control males or females. The reason for this lack of differences might be the fact that the hearing loss in heterozygous subjects was localized at high frequencies $(8-16 \mathrm{kHz})$, whereas OAEs were recorded at frequencies up to $5 \mathrm{kHz}$. On the other hand, several studies have presented data showing that a high frequency hearing deficit can be reflected in changes of lower-frequency DPOAEs (Arnold et al. 1999, Avan et al. 1997, Groh et al. 2006). However, in our study a hearing impairment was demonstrated only using audiogram normalization, but not with the recording of OAEs.

An interesting result of our study is the finding that the hearing deterioration in c. $35 \mathrm{delG}$ heterozygous carriers was more profound in females than in males. Several previous papers suggested the possibility that sex differences in the brain and behavior may be mediated by genetic mechanisms that do not involve gonadal hormones (Blecher and Erickson 2007, Bocklandt and Vilain 2007). Thus, several mechanisms can be responsible for the observed differences in hearing loss between heterozygous males and females; however, for a fuller explanation of this fact, further studies are necessary.

In conclusion, the results of the present study document that computing normalized audiograms for age and sex seems to be a suitable method for detecting slight differences in the audiograms of a relatively small number of subjects exhibiting a large variability in their ages. In addition, because the differences appeared at frequencies higher than $8 \mathrm{kHz}$, these results demonstrate the importance of using audiometry over an extended frequency range as well as the use of new normalization coefficients for $10-16 \mathrm{kHz}$ to detect slight hearing impairments as observed in c.35delG heterozygous females.

\section{Conflict of Interest}

There is no conflict of interest.

\section{Acknowledgements}

Supported by the project (Ministry of Health, Czech Republic) for conceptual development of research organization 00064203 (University Hospital Motol, Prague, Czech Republic) and by grants GACR 304/12/1342 and GACR P304/10/1872. The preliminary data were presented at the 45th Inner Ear Biology Workshop, September 21-24, 2008, Ferrara, Italy, and published as an abstract in the Workshop Proceedings.

\section{References}

ARNOLD DJ, LONSBURY-MARTIN BL, MARTIN GK: High-frequency hearing influences lower-frequency distortion-product otoacoustic emissions. Arch Otolaryngol Head Neck Surg 125: 215-222, 1999.

AVAN P, ELBEZ M, BONFILS P: Click-evoked otoacoustic emissions and the influence of high-frequency hearing losses in humans. J Acoust Soc Am 101: 2771-2777, 1997.

BLECHER SR, ERICKSON RP: Genetics of sexual development: a new paradigm. Am J Med Genet A 143: 3054-3068, 2007.

BOCKLANDT S, VILAIN E: Sex differences in brain and behavior: hormones versus genes. Adv Genet 59: 245-266, 2007.

COHN ES, KELLEY PM: Clinical phenotype and mutations in connexin 26 (DFNB1/GJB2), the most common cause of childhood hearing loss. Am J Med Genet 89: 130-136, 1999.

ENGEL-YEGER B, ZAAROURA S, ZLOTOGORA J, SHALEV S, HUJEIRAT Y, CARRASQUILLO M, BARGES S, PRATT H: The effects of a connexin 26 mutation - 35delG - on oto-acoustic emissions and brainstem evoked potentials: homozygotes and carriers. Hear Res 163: 93-100, 2002.

FRANZÉ A, CARAVELli A, Di LEVA F, MARCIANO E, AULETTA G, D'AULOS F, SAULINO C, ESPOSITO L, CARELLA M, GASPARINI P: Audiometric evaluation of carriers of the connexin 26 mutation $35 \mathrm{delG}$. Eur Arch Otorhinolaryngol 262: 921-924, 2005.

GROH D, PELANOVA J, JILEK M, POPELAR J, KABELKA Z, SYKA J: Changes in otoacoustic emissions and high-frequency hearing thresholds in children and adolescents. Hear Res 212: 90-98, 2006.

HOLT JR, COREY DP: Ion channel defects in hereditary hearing loss. Neuron 22: 217-219, 1999. 
ISO 7029 2000. Acoustics - Statistical distribution of hearing thresholds as a function of age. Geneva: International Organization for Standardization.

JILEK M, SYKA J: Age related hearing thresholds in an extended frequency range. The XIV International Symposium in Audiological Medicine, IAPA 2008, Ferrara, Italy, September 18-21, 2008, Abstract Proceedings p. 55, 2008.

KELSELL DP, DUNLOP J, STEVENS HP, LENCH NJ, LIANG JN, PARRY G, MUELLER RF, LEIGH IM: Connexin 26 mutations in hereditary non-syndromic sensorineural deafness. Nature 387: 80-83, 1997.

KIKUCHI T, ADAMS JC, MIYABE Y, SO E, KOBAYASHI T: Potassium ion recycling pathway via gap junction systems in the mammalian cochlea and its interruption in hereditary nonsyndromic deafness. Med Electron Microsc 33: 51-56, 2000.

LIPAN M, OUYANG X, YAN D, ANGELI S, DU LL, LIU XZ: Clinical comparison of hearing-impaired patients with DFNB1 against heterozygote carriers of connexin 26 mutations. Laryngoscope 121: 811-814, 2011.

MURGIA A, ORZAN E, POLLI R, MARTELLA M, VINANZI C, LEONARDI E, ARSLAN E, ZACCHELLO F: Cx26 deafness: mutation analysis and clinical variability. J Med Genet 36: 829-832, 1999.

PETERSEN MB, WILLEMS PJ: Non-syndromic, autosomal-recessive deafness. Clin Genet 69: 371-392, 2006.

SEEMAN P, MALÍKOVÁ M, RASKOVÁ D, BENDOVÁ O, GROH D, KUBÁLKOVÁ M, SAKMARYOVÁ I, SEEMANOVÁ E, KABELKA Z: Spectrum and frequencies of mutations in the GJB2 (Cx26) gene among 156 Czech patients with pre-lingual deafness. Clin Genet 66: 152-157, 2004.

SILVA LS, NETTO RC, SANCHES SG, CARVALLO RM: Auditory measurements in parents of individuals with autosomal recessive hearing loss. Pro Fono 22: 403-408, 2010.

WILCOX SA, SAUNDERS K, OSBORN AH, ARNOLD A, WUNDERLICH J, KELLY T, COLLINS V, WILCOX LJ, MCKINLAY GARDNER RJ, KAMARINOS M, CONE-WESSON B, WILLIAMSON R, DAHL HH: High frequency hearing loss correlated with mutations in the GJB2 gene. Hum Genet 106: 399-405, 2000. 